УДК 332.1

DOI 10.18101/2304-4446-2020-3-22-30

\title{
МЕХАНИЗМ ОБЕСПЕЧЕНИЯ ЭКОНОМИЧЕСКОЙ БЕЗОПАСНОСТИ С ПОЗИЦИИ ПРОСТРАНСТВЕННОГО РАЗВИТИЯ РЕГИОНОВ РФ
}

\author{
(C) Никулина Наталья Леонидовна \\ кандидат экономических наук, старший научный сотрудник \\ E-mail: nikulinanl@mail.ru
}

\author{
(C) Аверина Лидия Михайловна \\ младший научный сотрудник \\ E-mail: laverina@mail.ru
}

Институт экономики УрО РАН

Россия, 620014, г. Екатеринбург, ул. Московская, 29

В статье представлен анализ угроз экономической безопасности в пространственном аспекте. В ходе исследования определено, что основными угрозами экономической безопасности с точки зрения пространственного развития являются неравномерность пространственного развития территорий, усиление дифференциации территорий по уровню и темпам социально-экономического развития. Единство экономического пространства является важнейшим условием экономической безопасности страны и одним из критериев ее текущего уровня. Авторами рассмотрены показатели и методы, используемые для диагностики угроз экономической безопасности с точки зрения организации пространства: оценка уровня экономической интеграции, связанности, межрегиональных взаимодействий. Для анализа уровня межрегиональной интеграции предложено использовать информацию об инвестиционных проектах субъектов РФ, которые носят межрегиональный характер, что также позволит оценить состояние экономической безопасности пространственного развития. В статье рассмотрены комплексные межрегиональные инвестиционные проекты, реализация которых является действенным механизмом обеспечения экономической безопасности.

Ключевые слова: экономическая безопасность; угрозы экономической безопасности; пространственное развитие; интеграция; связанность; межрегиональное взаимодействие; механизм обеспечения; межрегиональные инвестиционные проекты; Стратегия экономической безопасности; Стратегия пространственного развития.

\section{Для цитирования}

Никулина Н. Л., Аверина Л. М. Механизм обеспечения экономической безопасности с позиции пространственного развития регионов РФ // Вестник Бурятского государственного университета. Экономика и менеджмент. 2020. № 3. С. 22-30.

Актуальность исследований в сфере обеспечения экономической безопасности регионов РФ со временем все более возрастает. Принятие в 2017 г. Стратегии экономической безопасности Российской Федерации на период до 2030 г. является подтверждением того, что экономическая безопасность важна для нормального, полноценного социально-экономического развития как отдельных регионов, так и Российской Федерации в целом.

Несомненно, имеется большой научный задел в разработке теоретических, методологических и методических положений, направленных на решение про- 

позиции пространственного развития регионов РФ

блем обеспечения экономической безопасности регионов РФ. Используемые в исследованиях разные подходы, рассмотрение проблемы в различных ракурсах, на разных уровнях, в разных сферах экономики - все это позволяет более детально и углубленно подходить к решению проблем экономической безопасности. В Стратегии экономической безопасности Российской Федерации дается следующее ее определение: экономическая безопасность - состояние защищенности национальной экономики от внешних и внутренних угроз, при котором обеспечиваются экономический суверенитет страны, единство ее экономического пространства, условия для реализации стратегических национальных приоритетов Российской Федерации. Далее, исходя из принятого определения, в Стратегии к основным вызовам и угрозам экономической безопасности с позиции пространственного развития отнесены: неравномерность пространственного развития Российской Федерации, усиление дифференциации регионов и муниципальных образований по уровню и темпам социально-экономического развития, наличие инфраструктурных ограничений для связанности пространства страны ${ }^{1}$. Таким образом, в Стратегии в качестве одного из критериев обеспечения экономической безопасности определено единство экономического пространства. Исходя из этого, предметом настоящего исследования является единство экономического пространства как фактор обеспечения экономической безопасности регионов РФ и России в целом.

В современной науке существует большое количество различных исследований, связанных с понятием «экономическое пространство». На наш взгляд, при рассмотрении экономического пространства с позиции экономической безопасности региона (страны) наиболее полное определение экономического пространства принадлежит А. Г. Гранбергу: «Экономическое пространство - это насыщенная территория, вмещающая множество объектов и связей между ними; населенные пункты, промышленные предприятия, хозяйственно освоенные и рекреационные площади, транспортные и инженерные сети и т. д.». А. Г. Гранберг в качестве основных характеристик пространства выделяет плотность (численность населения, объем валового регионального продукта, природные ресурсы, основной капитал и т. д. на единицу площади пространства); размещение (показатели равномерности, дифференциации, концентрации, распределения населения и экономической деятельности, в том числе существование хозяйственно освоенных и неосвоенных территорий); связанность (интенсивность экономических связей между частями и элементами пространства, условия мобильности товаров, услуг, капитала и людей, определяемые развитием транспортных и коммуникационных сетей) [1, с. 25].

В Стратегии экономической безопасности ${ }^{2}$ определены основные 40 показателей состояния экономической безопасности, но только один показатель из предложенных 40 предназначен для оценки угроз экономической безопасности с

${ }^{1}$ Стратегия экономической безопасности Российской Федерации на период до 2030 года. Утв. Указом Президента РФ от 13 мая 2017 года № 208 [Электронный ресурс]. URL: https://www.garant.ru/products/ipo/prime/doc/71572608/ (дата обращения: 08.04.2020).

${ }^{2}$ Стратегия экономической безопасности Российской Федерации на период до 2030 года. Утв. Указом Президента РФ от 13 мая 2017 года №208 [Электронный ресурс]. URL: https://www.garant.ru/products/ipo/prime/doc/71572608/ (дата обращения: 08.04.2020). 
точки зрения организации пространства - это уровень экономической интеграции субъектов Российской Федерации. Имеющийся зарубежный и отечественный опыт доказывает, что эффективным механизмом экономической интеграции регионов выступают межрегиональные взаимодействия. В России эффективность использования данного механизма была доказана, в частности, деятельностью межрегиональных ассоциаций экономического взаимодействия ${ }^{1}$. Можно отметить положительный опыт деятельности Ассоциации экономического взаимодействия областей и республик Уральского региона «Большой Урал».

Учитывая значимость межрегиональных взаимодействий в повышении темпов экономического роста в стране, сокращении уровня межрегиональной дифференциации в социально-экономическом развитии субъектов РФ, повышении уровня экономической связанности территории РФ посредством расширения и модернизации транспортной инфраструктуры, этому вопросу уделяется большое внимание в стратегических документах развития страны, в том числе и в Стратегии пространственного развития Российской Федерации на период до 2025 г. ${ }^{2}$. В данном документе в качестве одного из важнейших направлений пространственного развития РФ отмечено усиление межрегионального сотрудничества и координации социально-экономического развития субъектов Российской Федерации в рамках макрорегионов.

В современной экономической науке вопросам межрегионального взаимодействия уделяется значительное внимание, о чем свидетельствует наличие достаточно большого числа научных публикаций. Обзор современной научной литературы по данной тематике, выполненный Ю. В. Дубровской [2], выявил наличие двух основных направлений в исследовании вопросов межрегионального взаимодействия, которые рассматриваются: во-первых, с позиции глобализации [3; 4], во-вторых, с точки зрения неравномерности пространственного регионального развития [5-7]. При этом посвященные теме межрегионального взаимодействия публикации рассматривают данный вопрос применительно к различным сферам деятельности: приграничное сотрудничество (его роль в общей системе межрегиональных взаимодействий приграничных регионов) [8]; инновационная деятельность (в частности, выявление взаимосвязи уровня межрегионального взаимодействия и инновационной активности регионов) [9; 10]; межрегиональная торговля [11-13]; интеграция стран (регионов) в мировое хозяйство ${ }^{3}[14 ; 15]$.

${ }^{1}$ С лета 1991 года в России стали создаваться межрегиональные ассоциации экономического взаимодействия - координационные структуры органов исполнительной и законодательной власти субъектов РФ. Всего к началу 1999 года создано 8 ассоциаций, охватывающих всю территорию России (кроме Чечни). По каждой ассоциации принималось распоряжение соответствующего органа власти РФ, в котором регионам, вступившим в ассоциацию, предоставлялись значительные экономические льготы. Через деятельность данных ассоциаций осуществлялась организация межрегионального взаимодействия.

${ }^{2}$ Стратегия пространственного развития Российской Федерации на период до 2025 года. Утв. распоряжением Правительства Российской Федерации от 13 февраля 2019 г. № 207-p [Электронный pecypc]. URL: http:/static.government.ru/media/files/ UVAlqUtT08o60RktoOX122JjAe7irNxc.pdf (дата обращения: 15.04.2020).

${ }^{3}$ Система индикаторов интеграции как инструмент анализа функционирования региональных интеграционных объединений [Электронный pecypc]. URL: 
Н. Л. Никулина, Л. М. Аверина. Механизм обеспечения экономической безопасности с позиции пространственного развития регионов РФ

В научной среде существуют различные подходы, различные методики определения уровня межрегионального взаимодействия, осуществляемого в различных сферах экономики, в регионах разного типа и др.

На наш взгляд, особый интерес вызывает анализ территориальных взаимосвязей, осуществляемый методами пространственной автокорреляции и кластеризации (В. Алонсо [16], Л. Анселин [17], Р. Гири [18], П. Моран [19] и др.). Исследования межрегиональных корреляционных взаимосвязей с использованием данных методов для показателей социально-экономического развития проводили В.А. Балаш, А. Р. Файзлиев [20], Ю. В. Павлов, Е. Н. Королева [21], И. В. Наумов [22] и др.

Проведение двухэтапной процедуры кластеризации с использованием иерархических и неиерархических методов, как считают Н. Ю. Сорокина, Г. Ю. Гагарина, Р. В. Губарев, Н. Е. Бондаренко, также позволит оценить уровень экономической интеграции субъектов Российской Федерации [23].

Как подчеркивалось выше, межрегиональные взаимодействия - механизм экономической интеграции регионов. Подчеркивая значение экономической интеграции на уровне субъектов РФ, Г. Барсегян отмечает, что «региональная экономическая интеграция - ключевой фактор экономической связанности» ${ }^{1}$.

Проблемам экономической связанности регионов уделяют значительное внимание и другие отечественные исследователи. В. Б. Брюханова и Д. С. Бартаева предлагают оценивать экономическую и социальную связанность отдельных частей регионального экономического пространства с помощью гравитационного и картографического методов. Результатом их исследования является группировка районов Республики Бурятия по их связанности с центром. Гравитационная модель, предлагаемая авторами, основана на измерении силы притяжения района к центру, прямо пропорциональную произведению численности населения в обоих пунктах и обратно пропорциональную квадрату расстояния между этими пунктами. В качестве коэффициента соответствия авторами предложен учет соотношения плотности предприятий в центре и районе, в число которых входят малые предприятия, характеризующие инновационную активность центра и периферии [24].

Эффективная трансформация пространственной организации российской экономики диктует необходимость поиска механизмов, методов, форм межрегионального взаимодействия, направленных на формирование единого экономического пространства страны. Одним из действенных механизмов, на наш взгляд, является разработка комплексных межрегиональных инвестиционных проектов. Условием эффективности данных проектов является четко обозначенная цель, достижение которой обеспечивает эффекты для всех участников проекта (население, госкорпорации, бизнес-структуры субъектов РФ), а заинтересованность государства заключается в возможности решения в рамках данного проекта ряда

http://www.eurasiancommission.org/ru/act/integr_i_makroec/dep_makroec_pol/developDocs/D ocuments/\%D0\%98\%D0\%BD\%D0\%B4\%D0\%B8\%D0\%BA\%D0\%B0\%D1\%82\%D0\%BE\%D $1 \% 80 \% \mathrm{D} 1 \% 8 \mathrm{~B} \% 20 \% \mathrm{D} 0 \% \mathrm{~B} 8 \% \mathrm{D} 0 \% \mathrm{BD} \% \mathrm{D} 1 \% 82 \% \mathrm{D} 0 \% \mathrm{~B} 5 \% \mathrm{D} 0 \% \mathrm{~B} 3 \% \mathrm{D} 1 \% 80 \% \mathrm{D} 0 \% \mathrm{~B} 0 \% \mathrm{D}$ 1\%86\%D0\%B8\%D0\%B8\%202019.pdf (дата обращения: 15.04.2020).

${ }^{1}$ Страны ЕАЭС и ЕС могут развивать экономическую связанность в Евразии [Электронный ресурс]. URL: http://www.eurasiancommission.org/ru/nae/news/Pages/09-11-20181.aspx_(дата обращения: 08.04.2020). 
задач общегосударственного значения, в т. ч. в сфере национальной безопасности. Примером подобного проекта является межрегиональный проект «Арктический вектор Уральского созвездия», разработанный Институтом экономики УрО РАН, инициированный к разработке Правительством Свердловской области [25].

Данный проект является примером эффективного взаимодействия в рамках межрегионального проекта регионов с разной структурой экономики и различным уровнем социально-экономического развития. Партнерами в проекте выступают, с одной стороны, регионы «Уральского созвездия» (индустриальноразвитые регионы Урала и сопредельные субъекты Приволжского федерального округа, основу промышленности которых составляет тяжелая индустрия), с другой стороны - Ямало-Ненецкий и Ханты-Мансийский автономные округа, в которых основу экономики составляют добыча и транспортировка углеводородов с высокой долей экспорта. На территории округов осуществляются крупные проекты в сферах разработки месторождений углеводородов и переработки углеводородного сырья, для реализации которых требуется современное оборудование и инновационные технологии. На территории ЯНАО осуществляются крупные транспортные проекты федерального значения: начато строительство двух железнодорожных магистралей («Бованенково - порт «Сабетта» и «Северный широтный ход»), проводятся мероприятия по дальнейшему развитию многофункционального морского порта «Сабетта». Данные транспортные проекты и инвестиционные проекты нефтегазодобывающих компаний на территории ЯНАО и ХМАО способны обеспечить уральским предприятиям, с учетом их производственной специализации, огромный рынок сбыта продукции (машины и оборудование, трубы, железнодорожные рельсы, строительные материалы и др.).

Основной целью проекта «Арктический вектор Уральского созвездия» является формирование единого реестра предложений уральских предприятий по возможным поставкам оборудования, в т. ч. импортозамещающего, произведенного с учетом климатических условий его эксплуатации. Формирование реестра выпускаемой и перспективной продукции осуществляется на основе учета возможностей предприятий регионов, их существующей и перспективной технологической и производственной кооперации, разработок уральской науки. Интеграция совместных усилий предприятий уральских регионов по производству и продвижению их продукции на арктический рынок позволит им занять емкую нишу на перспективном арктическом рынке продукции.

Участие уральских предприятий в осуществлении транспортных проектов обеспечит реализацию данных проектов в прогнозные сроки, что имеет особое значение в условиях действия западных санкций. В то же время реализация транспортных проектов на территории ЯНАО обеспечит выход экспортных грузопотоков уральских предприятий к Северному морскому пути через порт «Сабетта», что имеет большое значение для уральской промышленности, характеризующейся экспортно ориентированной направленностью.

Таким образом, реализация межрегионального проекта «Арктический вектор Уральского созвездия» окажет положительное влияние на экономику регионов - участников межрегионального взаимодействия, а с точки зрения нацио- 
Н. Л. Никулина, Л. М. Аверина. Механизм обеспечения экономической безопасности с позиции пространственного развития регионов РФ

нальных интересов будет способствовать экономической целостности страны и ее безопасности.

Большой практический интерес с позиции обеспечения связанности территории страны и интересов ее экономической безопасности представляет интеграция инициатив отдельных субъектов РФ, входящих в состав определенного федерального округа, направленных на решение конкретной задачи, актуальной для каждого региона и отвечающей национальным интересам. Именно на уровне федерального округа, с учетом организационных и управленческих возможностей, наиболее вероятна интеграция инициатив его отдельных субъектов с проверкой их соответствия основным направлениям развития страны.

Для иллюстрации возможного эффекта от использования данного механизма межрегионального взаимодействия можно привести следующий пример. В 2019 г. полпредством Уральского федерального округа был инициирован сбор крупных (стоимостью свыше 1 млрд руб.) инвестиционных проектов межрегионального характера, представляемых субъектами РФ в составе данного округа. Институтом экономики УрО РАН был выполнен анализ представленных проектов и проектных инициатив. Всего было рассмотрено 66 проектов, требующих в совокупности привлечения более 3,3 трлн р. и предполагающих создание более 28 тыс. рабочих мест ${ }^{1}$.

Количество проектов, представленных каждым субъектом РФ, позволяет с некоторой долей вероятности оценить уровень межрегиональных взаимодействий между субъектами, направленных на решение общих проблем.

Таблица 1

Количество межрегиональных инвестиционных проектов

\begin{tabular}{|l|c|c|}
\hline \multicolumn{1}{|c|}{ Субъект УрФО } & $\begin{array}{c}\text { Количество } \\
\text { межрегиональных } \\
\text { инвестиционных проектов }\end{array}$ & $\begin{array}{c}\text { Доля } \\
\text { в общем количестве } \\
\text { проектов, \% }\end{array}$ \\
\hline Курганская область & $\mathbf{5}$ & $\mathbf{7 , 6}$ \\
\hline Свердловская область & $\mathbf{1 0}$ & $\mathbf{1 5 , 2}$ \\
\hline Челябинская область & $\mathbf{2 8}$ & $\mathbf{4 2 , 4}$ \\
\hline Тюменская область (без округов) & 13 & $\mathbf{1 9 , 7}$ \\
\hline ХМАО & $\mathbf{7}$ & $\mathbf{1 0 , 6}$ \\
\hline ЯНАО & $\mathbf{3}$ & $\mathbf{4 , 5}$ \\
\hline Итого & $\mathbf{6 6}$ & $\mathbf{1 0 0}$ \\
\hline
\end{tabular}

Наибольшее количество инвестиционных проектов, носящих межрегиональный характер, представлен администрацией Челябинской области. Это объясняется значительным количеством проектов предприятий металлургического комплекса, входящих в состав межрегиональных холдинговых структур.

В таблице 2 представлена группировка проектов по сферам их реализации.

${ }^{1}$ Кроме проектов, субъектами были представлены около сотни проектных инициатив, большинство из них не было достаточно обосновано, поэтому в анализе они не были учтены. 
Распределение межрегиональных инвестиционных проектов по сферам реализации

\begin{tabular}{|l|c|}
\hline \multicolumn{1}{|c|}{ тип инвестиционного проекта } & $\begin{array}{c}\text { Доля в общем количестве } \\
\text { инвестиционных проектов, \% }\end{array}$ \\
\hline Производственный (промышленность) & $\mathbf{2 7}$ \\
\hline Производственный (АПК) & $\mathbf{2 3}$ \\
\hline Инфраструктурный (транспорт и логистика) & $\mathbf{8}$ \\
\hline Инфраструктурный (социальная сфера) & $\mathbf{2}$ \\
\hline Инфраструктурный (инновации) & $\mathbf{1}$ \\
\hline Инфраструктурный (ЖКХ) & \\
\hline
\end{tabular}

Наибольший удельный вес в числе представленных межрегиональных проектов составляют проекты в области промышленности и транспортнологистической инфраструктуры. Выполненная Институтом экономики УрО РАН оценка социально-экономического положения субъектов УрФО позволила определить основные проблемы их развития, выявить имеющиеся диспропорции, конкретные для каждого региона, и показала наличие общей для всех субъектов округа проблемы - несоответствие состояния транспортно-логистической инфраструктуры экономическому потенциалу регионов. Таким образом, был сделан вывод: наиболее востребованной является интеграция инициатив субъектов РФ в Уральском федеральном округе в сфере формирования единой транспортно-логистической системы на основе взаимодействия различных видов транспорта. Было обосновано, что создание единой сбалансированной транспортнологистической инфраструктуры округа с выходом на другие территории страны и международные транспортные коридоры не только обеспечит опережающее экономическое развитие субъектов УрФО, но и будет способствовать связанности территории страны и ее экономической безопасности.

\section{Благодарность}

Статья подготовлена в соответствии с Планом НИР для Лаборатории моделирования пространственного развития территорий ФГБУН Института экономики УрО РАН на 2020 год.

\section{Литература}

1. Гранберг А. Г. Основы региональной экономики: учебник для вузов. 2-е изд. М.: ГУ ВШЭ, 2001. 495 с.

2. Дубровская Ю. В. Инструменты и институты активизации межрегионального взаимодействия в отечественной экономике // Вестник Омского университета. 2017. № 4(60). C. 34-44. DOI: 10.25513/1812-3988.2017.4.34-44. - (Экономика).

3. Torre A., Rallet A. Proximity and Localization // Regional Studies. 2005. Vol. 39(1). P. 47-59. DOI: 10.1080/0034340052000320842.

4. Etzioni A. Political unification: a comparative study of leaders and forces. New York: Rinehart and Winston, 1965. $346 \mathrm{p}$.

5. Industrial districts and local economic regeneration / ed. by F. Pyke, W. Sengenberger. Geneva: ILO, 1992. 294 p. 
Н. Л. Никулина, Л. М. Аверина. Механизм обеспечения экономической безопасности с позиции пространственного развития регионов РФ

6. Song W. Regionalization, inter-regional cooperation and global governance // Asia Europe Journal. 2007. Vol. 5, iss. 1. P. 67-82. DOI: https://doi.org/10.1007/s10308-006-0094-y.

7. Плихун О. Г., Киселев А. М. Вопросы межрегионального и приграничного сотрудничества Омской области // Вестник Омского университета. 2009. № 3. С. 56-59. (Экономика).

8. Межевич Н. М., Жук Н. П. Методика оценки приграничной специализации межрегиональных взаимодействий приграничных регионов и результаты пилотной оценки // Балтийский регион. 2013. № 1. С. 38-52.

9. Аверина Л. М., Сиротин Д. В. Оценка пространственных эффектов от инновационной активности промышленно развитых регионов РФ // Экономика региона. 2020. T. 16, вып. 1. С. 268-282. DOI: https://doi.org/10.17059/2020-1-20.

10. Золотарев Н. П. Механизм межрегионального экономического взаимодействия в инновационной сфере: потребность развития, сущность, показатели оценки // Вестник ТГПУ (ТSPU Bulletin). 2012. № 12(127). С. 127-132.

11. Малышева Т. В., Кандилов В. П., Николаев А. В. Конкурентоспособность продукции: информационно-аналитическая система «Продвижение товаров Республики Татарстан на внешние рынки» // Вопросы статистики. 2015. № 4. С. 57-66.

12. Топилин А. В., Ростанец В. Г., Кабалинский А. И. Межрегиональные и межмуниципальные связи как средство преодоления дезинтеграционных тенденций в экономическом пространстве России // Вестник Российской академии естественных наук. 2015. № 6. С. 97-104.

13. Беляевская-Плотник Л. А., Сорокина Н. Ю. Подходы к оценке уровня экономической интеграции регионов в системе национальной экономической безопасности // Экономические науки. 2017. № 6(151). С. 39-43.

14. Александров Г. А., Розов Д. В., Скворцова Г. Г. К вопросу о показателях национальной экономической безопасности: исторический и современный аспекты // Экономические отношения. 2019. Т. 9, № 4. С. 2833-2850. DOI: 10.18334/eo.9.4.40951.

15. Горецкая Е. О., Косулина Т. А. Методы оценки степени интеграции субъектов Южного федерального округа Российской Федерации в мировую экономику // Региональная экономика: теория и практика. 2011. Т. 9, вып. 46. С. 10-19.

16. Alonso W. Location and Land Use. Cambridge. MA: Harvard University Press, 1964. $206 \mathrm{p}$.

17. Anselin L. Spatial Econometrics: Methods and Models. Dordrecht: Kluwer Academic Publishers, 1988. 304 p.

18. Geary R. The continiguity ratio and statistical mapping // The Incorporated Statistician. 1954. № 5. P. 115-145.

19. Moran P. The interpretation of statistical maps // Journal of the Royal Statistical Society. 1948. № 10. P. 243-251. (Series B).

20. Балаш В. А., Файзлиев А. Р. Пространственная корреляция в статистических исследованиях // Вестник Саратовского государственного социально-экономического университета. 2008. № 4(23). С. 122-125.

21. Павлов Ю. В., Королева Е. Н. Пространственные взаимодействия. Оценка на основе глобального и локального индексов Морана // Пространственная экономика. 2014. № 3. C. 95-110. DOI: 10.14530/se.2014.3.95-110.

22. Наумов И.В. Исследование межрегиональных взаимосвязей в процессах формирования инвестиционного потенциала территорий методами пространственного моделирования // Экономика региона. 2019. Т. 15, вып. 3. С. 720-735. DOI: 10.17059/2019-3-8.

23. Концептуальные основы диагностики уровня экономической интеграции субъектов Российской Федерации / Н. Ю. Сорокина, Г. Ю. Гагарина, Р. В. Губарев, Н. Е. Бондаренко // Плехановский научный бюллетень. 2018. № 2(14). С. 131-141. 
24. Брюханова В. Б., Бартаева Д. С. Методы анализа пространственного развития региона // Экономика: вчера, сегодня, завтра. 2016. Т. 6, № 12А. С. 347-357.

25. Арктический вектор Уральского созвездия. Пояснительная записка / Л. М. Аверина [и др.]. Екатеринбург: Институт экономики УрО РАН, 2018. 77 с.

\section{MECHANISM FOR ENSURING ECONOMIC STABILITY \\ FROM THE PERSPECTIVE OF THE SPATIAL DEVELOPMENT OF RUSSIA'S CONSTITUENT REGIONS}

Natalya L. Nikulina

Cand. Sci. (Econ.), Senior Researcher

E-mail: nikulinanl@mail.ru

Lidiya M. Averina

Junior Researcher

E-mail: laverina@mail.ru

Institute of Economics, Ural Branch of RAS

29 Moskovskaya St., Ekaterinburg 620014, Russia

The article presents an analysis of threats to economic stability in a spatial aspect. The study have shown that the main threats to economic stability from the perspective of spatial development are the uneven spatial development of territories, the increased differentiation of territories in terms of the level and pace of socio-economic development. The unity of the economic space is the most important condition for the country's economic security and one of the criteria of its current state. We have considered the indicators and methods used to diagnose threats to economic stability from the perspective of organizing space: the assessment of the level of economic integration, coherence, interregional interactions. To analyze the level of interregional integration it is proposed to use information on the investment projects of Russia's constituent entities, which allow assessing the state of economic security of spatial development due to the interregional nature of such projects. The article analyzes complex interregional investment projects, which implementation is an effective mechanism for ensuring economic stability.

Keywords: economic stability; threats to economic stability; spatial development; integration; coherence; interregional interaction; facilitating mechanism; interregional investment projects; economic security strategy; spatial development strategy. 